\title{
Por uma clínica da resistência: experimentações desinstitucionalizantes em tempos de biopolítica
}

Roberta Carvalho Romagnoli ${ }^{1}$

Simone Mainieri Paulon ${ }^{2}$

Ana Karenina de Melo Arraes Amorim ${ }^{3}$

Magda Dimenstein ${ }^{4}$

\section{Tempos de biopolítica}

Quando Michel Foucault estudou as relações de poder, com certeza, o mundo era outro. Em sua genealogia, iniciada nos anos 70, o filósofo considerava a sociedade disciplinar, e, nesse contexto, eram as instituições que detinham o poder, ao qual denominaria biopoder. Gerado a partir do século XVIII, esse "poder sobre a vida" ganha força nos conhecimentos científicos e passa a afastar as ameaças de morte, sempre presentes até então. "No terreno assim conquistado, organizando-o e ampliando-o, os processos da vida são levados em conta por procedimentos de poder e de saber que tentam controlá-los, modificá-los" (Foucault, 1993, p.134). Esse controle se dava por meio das técnicas de poder presentes no corpo social que eram utilizadas pelas instituições, tais como: a família, a escola, a medicina, os asilos, dentre outras. Atuantes por meio de práticas discursivas, tais técnicas de poder convocavam a realidade a ser produzida a partir de processos disciplinares que se destinavam a gerir a vida sustentando-se por normas - ideias construídas às quais se concede o status de verdade, que transitam por todos os eixos do poder, e em torno delas as pessoas são estimuladas a moldarem e a fabricarem suas vidas, seu dia-a-dia.

Cabe ressaltar que o biopoder atua em dois eixos, um disciplinar e outro biopolítico. Em seu polo disciplinar, o poder centrava-se no corpo como máquina, para adestrá-lo, ampliar suas aptidões, aumentar sua utilidade e docilidade, em um processo assegurado pelas disciplinas. Em seu polo biopolítico, o poder centrava-se no corpo como espécie, por meio de processos reguladores da população, para controlar os nascimentos e mortes, epidemias, o nível de saúde, a duração da vida. Com um funcionamento menos repressivo e punitivo e mais constitutivo e determinante, esse poder participa ativamente da produção de modos de subjetivação, da elaboração do cotidiano das pessoas, sujeitando-as a verdades normativas que prefixam sua vida e as suas relações. Dessa maneira, da ligação entre saber e poder emergem os sistemas de vigilância, praticada, em última instância, por todos os campos de saber.

A ideia de um movimento que torna a vida e seus mecanismos inseridos no domínio político e faz do poder-saber uma estratégia de alteração da vida
1 Programa de PósGraduação em Psicologia Pontifícia Universidade Católica de Minas Gerais. Rua Terra Nova, 101/401, Sion, Belo Horizonte, MG, Brasil. 30. 315-470 robertaroma@uol.com.br ${ }_{2}^{2}$ Mestrado em

Psicologia Institucional, Universidade Federal do Rio Grande do Sul. ${ }^{3}$ Departamento de Psicologia, Universidade Federal do Rio Grande do Norte.

${ }^{4}$ Programa de PósGraduação em Psicologia Social, Universidade Federal do Rio Grande do Norte. 
humana em seu eixo biopolítico, embora lançada por Michel Foucault, não chegou a ser devidamente absorvida e trabalhada por ele.

Embasado nas mudanças sociais da última década, Deleuze (1992) compreende a substituição da sociedade disciplinar, tal como caracterizada por Michel Foucault, para o que denominará uma "sociedade de controle". Para o referido filósofo, enquanto a sociedade disciplinar tinha nas instituições os seus estabelecimentos de monitoramento e vigilância, regulando os indivíduos no polo disciplinar, as massas no polo biopolítico e, nas disciplinas, sua fundamentação, a sociedade de controle possui um funcionamento por redes flexíveis, modulares, estendendo, cada vez mais, seus domínios de ação sobre a subjetividade. Por meio dos avanços da informática, do marketing, da comunicação virtual, presenciamos uma fluidez dos mecanismos de controle, em que "[...] O controle é de curto prazo e de rotação rápida, mas também contínuo e ilimitado, ao passo que a disciplina era de longa duração, infinita e descontínua. O homem não é mais o homem confinado, mas o homem endividado" (Deleuze, 1992, p.224).

Esse pressuposto deleuziano fundamenta as ideias de Hardt e Negri (2001), que, em seu livro Império, fazem uma revisão do conceito de biopolítica e um deslocamento da biopolítica dos processos biológicos que incidem sobre os corpos e a população - como utilizado por Michel Foucault - para a sua articulação com a própria noção de vida. A partir das mudanças ocorridas no mundo globalizado, tais como o enfraquecimento da sociedade civil e a instauração de instituições transnacionais e do mercado mundial, o que antes era produzido geralmente dentro das instituições, agora se estende imanentemente para todo o campo social de maneira quase imperceptível. Essa sutileza se ampara na possibilidade imensurável de escolhas e caracteriza-se por um processo fluido de produção da subjetividade em que o poder, agora denominado de biopolítica, encontra-se calcado em fazer viver e em multiplicar as formas de existência, em controlar as condições de vida. Esse controle opera em rede e está em todos os lugares na ordem do dia, administrando as formas de vida e seu cotidiano.

Para Hardt (2000), o mundo globalizado evidencia a sociedade mundial de controle, que apresenta novas formas de poder. Em seu funcionamento, os fluxos - sejam eles de capital, de informação, de serviços, de bens, de imagens - circulam por toda parte, geridos pela ausência de limites concretos. Dessa maneira, o poder exercido pelo Império contemporâneo não apresenta fronteiras territoriais ou temporais, pois, cada vez menos, há uma distinção entre o "dentro" e o "fora", entre o que pertence a um território, a um país, a uma determinada cultura e o que está fora dessas dimensões. Os novos mecanismos de produção da subjetividade são mais difusos e móveis, uma vez que as instituições vivem o que o autor chama de "oni-crise", responsável pela diminuição de seu caráter de monitoramento. No entanto, a dispensa de mediações institucionais não os torna menos eficazes e, tampouco, ocasiona menos efeitos na gerência da vida.

Contudo, é preciso pontuar que a biopolítica é também potência de vida, não somente poder sobre a vida, e pode ser inventiva, força universal, principal fonte de valor. Sem dúvida, o poder exerce-se sobre uma potência subjetiva que, se convocada, pode tornar-se poder de resistência, virando a biopolítica pelo avesso. A vida, enquanto multiplicidade heterogênea detentora de linhas de virtualidade, também produz singularidades, não somente clones, como quando está a serviço da sociedade mundial de controle. Ou seja, o termo biopolítica passa a designar, assim, potência da vida, tanto para ser explorada, serializada, homogeneizada, quanto para atuar como resistência em estreita associação com a invenção.

Atualmente, mediante esse novo funcionamento do corpo social, a resistência não se liga somente à oposição direta do campo de forças descrito acima, mas também e, sobretudo, à produção de dispositivos singulares que não estejam a serviço da serialização instituída. Isso porque a força-invenção da vida não se encontra totalmente capturada pelo capital, pois é exatamente no que o poder investe que também se ancora sua resistência. Sem dúvida, a vida é em si uma potência, que funda e dispara singularidades. E o agenciamento com essa força intensiva conduz à resistência, à invenção.

Os processos de desinstitucionalização, como aqui os estamos concebendo, inscrevem-se neste modo de funcionar característico das sociedades de controle contemporâneas. Já não se pode, nesta lógica, pensar formas de liberação do desejo circunscritas a espaços institucionais, mas antes na "tarefa da desinstitucionalização como incessante questionamento dos valores que atribuímos a nossas 
formações culturais, constante potencialização dos movimentos críticos às formas dadas que aparecem como naturais e incansável disposição a produzir o novo, resgatando o devir criador de cada um de nós" (Paulon, 2006, s/p).

No campo da saúde mental, de modo mais específico, esta tarefa faz-se especialmente desafiadora e emergente. A reforma psiquiátrica em curso no país estabelece um novo cotidiano de trabalho para os profissionais de saúde. Novas demandas que fogem aos cenários habituais de atuação, milenarmente arraigados à instituição manicomial, se impõem. Tamanha diversidade de demandas e intervenções, entretanto, não necessariamente significa correspondente superação das clausuras do desejo e da vontade de reproduzir. Uma mudança paradigmática no plano da lei ou, mesmo, dos dispositivos de cuidado é necessária, mas não suficiente para erradicar os desejos de dominar, controlar e oprimir o louco, que, usando uma terminologia cunhada por Machado e Lavrador (2001), evidenciam "desejos de manicômio". São desejos que expressam as marcas, linhas duras constitutivas de nossa subjetividade calcadas em mecanismos disciplinares que atrelam a loucura a saberes especializados e classificações psicopatológicas. São esses os desejos que mantêm os manicômios em atividade, não só empiricamente, mas também em nossa "alma", anônimos, dispersos e prontos para emergir a qualquer momento em defesa da exclusão.

A saída da instituição asilar e a oposição à lógica hospitalocêntrica, por si só, não significam que acabamos com os manicômios que nos habitam. Há ainda alguns aprisionamentos que nos impedem de inventar e de resistir e que geram nossas atuações, de forma sutil, mas nem por isso menos efetiva. A afirmação do que existe, o exercício de julgar e perseguir a semelhança, a separação entre saber e poder e as buscas de verdades transcendentes resguardam a tendência a validar e reproduzir recursos já existentes e institucionalizados e impedem a criação de novas formas de lidar com a loucura.

A desinstitucionalização no campo da saúde mental exige experimentações de um novo modo de cuidar. Experimentações que requerem uma disponibilidade de afetar e ser afetado, que pode estar em qualquer um, pode se expressar em qualquer espaço, pode demandar estranhos saberes, desde que a ousadia para o encontro com o diferente, o difícil e raro movimento em direção ao "não-eu" se faça presente.

É nesta perspectiva que a invenção de um novo modo de cuidar demanda conhecimentos plurais que superem as fronteiras disciplinares. Desse modo, não cabe mais separar a clínica da política, a saúde dos contextos que a produzem, pois se trata, muito mais, de afirmarmos uma clínica que se tece nessas tensões, intensificando e fazendo a vida vibrar em toda sua potência prenhe do diverso.

Considerando a realidade da atenção à saúde mental neste cenário de polarizações, entendemos que não podemos pensar nas questões relativas ao processo de desinstitucionalização sem operar uma análise das dificuldades e desafios encontrados no SUS, que envolvem outras problemáticas, como: as das práticas de saúde, a da chamada clínica ampliada e a da produção de saúde como produção de subjetividade.

No campo da saúde mental, a questão da inexistência ou da fragilidade de redes integradas na atenção especializada é trazida de forma evidente pelo mais novo dispositivo de cuidado implementado pela política nacional de saúde mental: o Serviço Residencial Terapêutico (SRT). Este foi proposto como equipamento de cuidado destinado a pessoas que têm história de longa internação em hospital psiquiátrico e perderam os vínculos familiares e sociais. O SRT seria, dessa forma, potencialmente livre de "cronicidades" de toda ordem e exigiria da rede de atenção e de todos os atores sociais envolvidos transformações e redimensionamentos para atender às suas demandas específicas.

É neste sentido que se torna estratégico, para o atual momento da Reforma, cartografarmos os fluxos e obstáculos que são colocados para que a atenção em saúde mental se efetive como uma rede integrada de cuidado. Um consequente mapeamento de forças e estratégias que sustentam as práticas de cuidado e o trabalho em saúde, a partir da diversidade de formas de vida que se desenvolvem cotidianamente nesta rede - e para além dela - se faria necessário para mapear os espaços de sociabilidade, solidariedade e convívio com a diferença que enfrentem as forças homogeneizantes e aprisionadoras das subjetividades.

Perguntamo-nos, assim, que transformações, que novos movimentos, que novas acomodações e que demandas os SRTs colocam para as redes de atenção em saúde mental e para cada um dos atores envolvidos no processo de cuidado e criação da vida dos seus moradores? Ou seja, que experimentações desinstitucionalizantes estão sendo possíveis ou impossibilitadas neste âmbito? Essa é 
a leitura e a perspectiva de compartilhar dificuldades e avanços que reúne os trabalhos realizados nos SRTs de dois extremos geográficos do país, Natal e Porto Alegre, tal como abordaremos a seguir.

\section{Cartografia do funcionamento do serviço residencial terapêutico de Natal}

O primeiro e único serviço residencial terapêutico da cidade de Natal conta hoje com sete moradores, que recebem cuidados de sete técnicos que se revezam nos três turnos durante todos os dias da semana, configurando um cuidado de natureza intensiva. Por ser um serviço novo, inaugurado há menos de três anos, nos interessamos em fazer um mapeamento inicial das problemáticas que enfrenta e os desafios postos à rede de saúde, e, a partir disso, vislumbramos algumas reflexões.

A primeira delas diz respeito ao fato de que, sendo uma experiência recente, guarda uma série de peculiaridades, dentre elas a não existência de modelos terapêuticos que ofereçam referências para a atuação dos técnicos nesta realidade. Isso produz, por exemplo, o desafio de se pensar o projeto terapêutico que se quer para este serviço. A esse respeito, os gestores, numa posição de aprendizes nesse processo reconhecidamente novo para todos os envolvidos, consideram a importância do respeito às singularidades de cada morador na construção de uma vida autônoma dentro das possibilidades de cada um, e reconhecem a necessidade de ações que promovam a reinserção social no ambiente comunitário, mas colocam alguns questionamentos, tais como: será necessário um projeto terapêutico para a residência? Fazemos projetos terapêuticos em nossas casas? Se não, por que fazermos para esta? Se os moradores têm a possibilidade de serem tratados pelo Centro de Atenção Psicossocial (CAPS) e, portanto, terem projetos terapêuticos próprios desenvolvidos neste serviço, por que construir um projeto específico para a residência? E essas são, de fato, questões que deixam evidente o que seria, talvez, o principal desafio destes dispositivos: o de realizar uma espécie de "clinica mínima" (Delgado, 2007, p.3), que torne esse espaço cada vez mais uma casa, em que o cotidiano possa ser vivido e o cuidado seja operacionalizado de modo que a vida comum e livre na cidade seja possível. Mas, como fazer, nessa experiência, experimentações desinstitucionalizantes em que os "projetos" em jogo sejam os diferentes "projetos de felicidade" (Ayres, 2004, p.85) dos moradores ganhando vida e possibilidades de concretização?

Essas questões abrem outras vias de problematização, tais como o questionamento das práticas de saúde e da atuação dos técnicos que estão cotidianamente nesse serviço. Considerando esses últimos, o que observamos é uma indefinição dos seus papéis/lugares em relação aos moradores e diferentes posturas em relação à atuação profissional que pode e deve ser desenvolvida ali. Estas posturas vão desde: a reflexão frente ao fato de que é uma experiência em construção, ao lado das preocupações éticas que elas exigem; a postura da reprodução de papéis familiares no cuidado, sem maiores reflexões sobre seus efeitos, e a posição de que o trabalho é em grande parte pedagógico-utilitário na orientação dos moradores em relação aos fazeres cotidianos em uma casa, acompanhado do cuidado com as medicações e idas ao CAPS. Em todos, no entanto, há a preocupação presente, no discurso, de fazer com que os usuários sejam "inseridos socialmente" e "ganhem mais e mais autonomia", considerando as limitações de cada um, advindas seja da institucionalização, seja pelas patologias de que sofrem, segundo observado em conversas informais com técnicos do referido serviço.

Outra questão que se apresenta é precisamente a da articulação com o CAPS e com os demais serviços da rede. No que diz respeito especificamente à atenção básica, são observadas várias dificuldades, tais como: problemas com a marcação de consultas, enfrentadas por qualquer usuário do SUS, falta de informação, descuido com o paciente, até a falta de capacitação dos profissionais e a não sensibilização para as demandas específicas destes usuários. Hoje os moradores recebem atenção de um posto de saúde próximo em algumas especialidades médicas, sem entrar na fila de espera, o que foi possível mediante "acordo" feito com a gerência do distrito sanitário. Assim, o que se tem é uma atenção especial que se obtém por "concessões especiais", e não pelo direito que estes usuários têm de serem atendidos em suas reais necessidades de saúde, respeitando-se o princípio da integralidade da atenção. Aqui o desafio é o da construção de redes efetivas de comunicação e ação entre a atenção básica e especializada, de modo a atender a estas diversas demandas em saúde apresentadas por esses moradores. 
Em relação à articulação com o CAPS a que esses moradores estão vinculados, tem-se desde a dificuldade de comunicação entre os técnicos dos dois serviços, e todos os desdobramentos e problemas que isso produz, até o questionamento em relação à necessidade de acompanhamento pelo CAPS e a regularidade das visitas dos moradores a este serviço para participarem de suas atividades e receberem medicação, sabendo-se que há uma equipe de saúde específica para a residência. Tal questionamento vem ganhando forças diante da recusa de uma das moradoras a ir ao CAPS, sob o argumento de que ali se sente "presa". Não seria aqui necessária a criação de um espaço de discussão sobre o que se pretende em relação a esses usuários/moradores? Quais são os projetos de cuidado para cada morador? Será que a vinculação do SRT com o CAPS não implica um acompanhamento que respeite as necessidades e demandas de saúde singulares a cada morador, o que exige a criação de alternativas de cuidado, que fogem ao script terapêutico colocado pelo modelo CAPS? Por sua vez, os técnicos do SRT não precisariam estabelecer também essa rede de contatos, que vai muito além da combinação dos horários de visitas e discussão da necessidade de certa medicação para certo morador com o CAPS?

O trabalho no SRT parece exigir também e, sobretudo, a tarefa de construção de redes de apoio e cuidado para além da casa e dos serviços, que envolva a cidade com suas diferentes e potentes geografias de cuidado. O SRT parece então colocar o desafio, para os diferentes atores envolvidos, da efetiva construção de redes de comunicação e ação para além dos serviços, o que implica a desnaturalização da "clínica" tal como ela vem sendo desenvolvida desde o interior dos serviços, especialmente dos CAPS.

Esses são, portanto, alguns dos pontos observados, que colocam o desafio de romper com a reprodução da lógica manicomial em operação nos novos serviços como o residencial. Mapear esses pontos de captura dos fluxos inventivos nos conduz também a rastrear focos de resistência biopolítica à reprodução e serialização. Concordamos com Machado e Lavrador (2007) que precisamos lutar contra a produção de hospitais psiquiátricos em miniatura e a imposição de modos de vida enrijecidos e tutelados, para que o cotidiano não seja a "[...] continuidade de uma pretensa 'ordem natural' de sujeição, de cronificação institucional e de desqualificação do outro, ao não se acreditar que os modos de vida possam ser transformados" (p.91). Para tanto, compartilhar experimentações nesse campo é imprescindível. Nesse sentido, seguimos com outros fazeres, com a experiência dos residenciais de Porto Alegre em seus movimentos de crítica e inventividade.

\section{Educação permanente em saúde como dispositivo de cuidado aos cuidadores dos Serviços residenciais terapêuticos}

O desafio de fazer de um lugar de moradia um espaço terapêutico sem que, com isso, o habitar fique reduzido ao "tratamento" é um questionamento reincidente, não só para as equipes de trabalhadores dos Residenciais Terapêuticos de Natal, no Rio Grande do Norte, mas também do Estado do Rio Grande do Sul. Inaugurados em diferentes momentos entre 2003 e 2006, os três SRTs situados em Porto Alegre (Morada São Pedro) ou redondezas (Viamão e Itapoã) reúnem quase quarenta funcionários cujos tempos de trabalho nos novos dispositivos e afinidades com os princípios da Reforma Psiquiátrica brasileira são igualmente variáveis. Entre as questões que aproximam este grupo heterogêneo encontra-se o desejo de aprender um novo modo de cuidar em saúde mental e a necessidade de compartilhamento das dificuldades que este aprendizado lhes têm imposto. Com tais demandas, procuraram os profissionais que tinham por referência da militância e trabalhos anteriores no estado e pediram ajuda. A partir da solicitação inicial de realização de uma Oficina de "cuidado do cuidador" ou de uma palestra para retomar os princípios da Reforma Psiquiátrica, foi construída uma proposta conjunta da coordenação dos SRTs, coordenação da política de saúde mental da SES e da psicologia da Universidade Federal do Rio Grande do Sul para realização de um programa de extensão junto àqueles trabalhadores (Paulon et al., 2007).

A fim de fomentar princípios desinstitucionalizantes da reforma psiquiátrica brasileira, desenvolvendo uma concepção do morar como dispositivo de cuidado, a extensão estruturou-se como um processo de Educação Permanente às equipes, desenvolvido ao longo de 2006, por meio de 
três frentes de ação, quais sejam: assessoria ao grupo gestor, seminários sistemáticos de capacitação das equipes de trabalhadores e supervisão de estágios em psicologia. A parceria estabelecida entre universidade / governo do Estado / trabalhadores dos residenciais propôs-se a: 1) sistematizar e divulgar as experiências de reforma psiquiátrica em curso no Estado; 2) possibilitar que os graduandos de psicologia tenham acesso a uma formação fundamentada no SUS, com ênfase nos dispositivos da Reforma Psiquiátrica, e 3) facilitar a constituição de práticas terapêuticas nas equipes de cuidadores dos SRTs que se aproximem de uma "Clínica do Morar".

O percurso desenvolvido com o grupo naquele primeiro ano, bem como as demandas de continuidade e ampliação que ele gerou, são indicadores de que os propósitos em torno dos quais se estruturou o programa de educação permanente tinham um sentido instituinte para o grupo de trabalhadores nele envolvido. Este sentido instituinte mostrou-se importante estratégia de resistência, exercício biopolítico, na acepção aqui assumida do termo. Que sentido era esse?

Algumas atividades do projeto de extensão contribuíram para que os trabalhadores fossem se apropriando do espaço acadêmico e aproveitando-o para forjarem novos sentidos singulares a seus processos de trabalho. Isto acontecia, por exemplo, nas reuniões quinzenais das coordenações das moradias que ocorriam na universidade - quando se assessoravam mutuamente -; nos encontros de planejamento dos espaços de capacitação mensal que faziam com suas equipes em espaços ordinários de reunião ou na participação colaborativa com a construção dos projetos de intervenção dos estagiários que se engajavam às equipes a partir da extensão. Ao fazê-lo, enfrentavam o desafio que era bem maior do que o tradicional sentido de "capacitarem-se" para uma tarefa que, para muitos, já era familiar. Enfrentavam o desafio de se desprenderem de velhas instituições que há muito lhes "ensinavam": como deviam cuidar, qual a "verdade" sobre o tratar, quem "sabe" como lidar com a loucura e quais os devidos espaços reservados para "tratá-la." Tamanha tarefa desinstitucionalizante ganha ainda maior importância no projeto de aprendizagem das novas formas de cuidar que a Reforma Psiquiátrica exige, se levamos em consideração o pedido inicial da equipe: aprenderem a transitar nas moradias diferentemente do que faziam nos corredores dos manicômios onde muitos aprenderam a trabalhar; desenvolverem um saber próprio que possa apoiar aquelas formas heterogêneas de ser e habitar, que os moradores dos SRTs Ihes apresentam; retirarem os manicômios de si mesmos, experimentando outros desejos de cuidar e aprender menos presos às amarras das instituições terapêuticas e escolares. Todas estas são estratégias de resistência no sentido de fazer frente ao que o exercício do biopoder das velhas instituições impõe, estendendo-se aos tempos de sociedade mundial de controle. A resistência aqui adquire um sentido biopolítico, produz a necessária inflexão ao lado das forças da vida que impede a captura absolutizante das formas reprodutoras.

O aprendizado de novas formas de cuidar e habitar, nessa medida, implica a apropriação de novos territórios subjetivos. Entre esses, encontra-se não somente o conhecido território-manicômio, ao qual as equipes sabem que devem resistir mesmo que nem sempre saibam exatamente como fazê-lo (para isto enunciam seu pedido de ajuda). Os territórios de saber especializado, o território acadêmico, os territórios de gestão igualmente precisam ser apropriados, no sentido mesmo de romper as tradicionais amarras institucionais que delimitam rígidas fronteiras do conhecimento aos detentores de algum "saber iluminado" a quem caberá um "poder ilimitado".

Neste sentido, borrar as fronteiras da gestão/atenção/educação; superar as fronteiras disciplinares do que cabe ao Estado/serviço/academia, assume uma conotação de resistência biopolítica que permite atribuir, a um mero programa de cuidado aos cuidadores, uma função de dispositivo desinstitucionalizante.

A análise da demanda contida no pedido "nos ensine uma forma reformista de trabalhar" foi transformada na produção da oferta "processo de educação permanente com as equipes dos SRTs". A problematização "de saída" daquele pedido, a constituição de fóruns coletivos de produção de um novo conhecimento acerca do trabalho desenvolvido pelas equipes, a ampliação das tarefas de coordenação e de ensino-aprendizagem que, inicialmente, caberiam às coordenadoras dos serviços e às professoras universitárias, respectivamente, foram algumas das estratégias utilizadas para se aproximarem as funções de atenção e gestão, ampliando consequentemente o grau de transversalidade nas equipes. 
Concluída a primeira etapa deste programa de extensão, podemos dizer que o programa de assessoria institucional parece ter contribuído para: 1) que a universidade possa cumprir seu papel social de interlocução com a comunidade, favorecendo a formação de novos profissionais da saúde na lógica da Reforma Psiquiátrica; 2) que os cuidadores dos novos equipamentos da rede de saúde mental compreendam suas posições institucionais enquanto agentes (mais ou menos qualificados, mas sempre implicados) da Reforma Psiquiátrica brasileira; 3) que os gestores analisem suas implicações com as instituições em jogo no exercício de suas funções de gestão, tomando-as também como práticas de cuidado.

Tais são as constatações que fazem com que um processo de Educação Permanente em Saúde possa ser concebido como dispositivo na lógica do cuidado para a autonomia, inscrevendo-se entre os princípios da Reforma Psiquiátrica; e que a Clínica possa ser entendida como indissociável da Política ao produzir efeitos desinstitucionalizantes e se afirmar micropoliticamente como exercício de resistência e criação: novos modos de cuidar da vida.

\section{Ao que resistir? Resistir por quê?}

As intervenções acima descritas reúnem experiências diversas em territórios longínquos que, no plano da discussão de certa concepção da clínica, permitem-nos algumas aproximações. A primeira delas diz respeito à questão do poder e da resistência no momento contemporâneo. A análise anteriormente empreendida convoca-nos a pensar que, se o poder sobre a vida não se reduz a sua faceta coercitiva, é preciso explorar e fazer vibrar o eixo biopolítico de um poder que também é poder de invenção de novas formas de viver, e, sobretudo, de atuar em nossas inserções profissionais.

No campo específico da saúde mental, isto equivale a dizer que é preciso assumir posturas mais ativas e singulares de enfrentamento das formas de poder. Esse enfrentamento deve se dar tanto no eixo disciplinar que o biopoder segue mantendo, mediante a sobrevivência de instituições arcaicas como o manicômio, na hegemonia do saber dos especialistas, e na fixação em práticas já estabelecidas; quanto no eixo biopolítico, por meio de improvisações e de inventividade que façam frente à administração das formas de vida e seu cotidiano - características da sociedade mundial de controle.

Isto equivale a se pensar na desinstitucionalização como ativação da força-invenção da vida. Desinstitucionalizar, na lógica da sociedade mundial de controle, não pode mais ser uma compreensão restrita às formas de poder institucional conhecidas no âmbito das sociedades disciplinares.

Desinstitucionalizar, agora, assume um significado mais fluido, que acompanha as novas formas de poder em rede e cria, por consequência, estratégias, também em rede, de resistir.

É neste aspecto que as experiências registradas nos serviços substitutivos criados pela mesma legislação nacional, em dois extremos do país, encontram uma segunda aproximação. Aproximação esta que aqui chamaremos de certa experiência clínica que não mais se compreende apartada da política, que não mais pode ser compreendida senão num registro da experiência coletiva.

Os desafios colocados pelos SRTs partem e destinam-se a diferentes espaços e atores envolvidos na atenção à saúde de seus moradores, assim como a construção efetiva de redes de cuidado na própria circulação dos moradores na cidade. A desconstrução da lógica manicomial requer intervenções no plano macropolítico - com iniciativas junto às políticas públicas que permitam estratégias e criação de espaços de vida "lá fora" e cuidado para com os moradores egressos de longas internações psiquiátricas, mas não só. Implica, também, construção de micropolíticas da diferença, com as quais os projetos de felicidade de todos e cada um sejam possíveis, como pequenas formas de resistência ao projeto hegemônico de felicidade, que uns poucos ou quase ninguém parece acessar.

Esse contexto de articulação entre a micropolítica e a macropolítica ancora a clínica em duas tarefas fundamentais para uma ação produtiva e transformadora da realidade: a identificação do que se repete, do que se instala como microfascismo no território clínico; e a ativação da potência de inventar novas maneiras de viver e de pensar.

De acordo com Romagnoli (2007), trata-se de uma orientação teórica que privilegia a composição ético-política de forças de diferentes naturezas, que emergem nos encontros, e que possibilita 
a invenção de novas formas de subjetivação. Essa clínica pressupõe uma articulação com a vida, refletindo acerca do espaço terapêutico como um dispositivo para a produção de processos de subjetivação singulares e inventivos, como uma tentativa de driblar a homogeneização, a reprodução de modos de existência tão presentes em nossa sociedade. Pensar a relação entre clínica e vida é, sobretudo, pensar também a política e os mecanismos cada vez mais sutis de dominação e de poder que gerenciam o cotidiano das subjetividades, em todos os domínios e aqui, mais especificamente, no território da reforma psiquiátrica em curso em nosso país.

\section{Colaboradores}

A proposta do artigo surgiu da mesa-redonda apresentada no V Congresso Norte Nordeste de Psicologia, em maio de 2007. Todos os autores contribuíram para a escrita e revisão do texto geral, com maior implicação nos seguintes tópicos: Roberta Carvalho Romagnoli: Tempos de Biopolítica; Simone Mainieri Paulon: Educação Permanente em Saúde como dispositivo de cuidado aos cuidadores dos Serviços Residenciais Terapêuticos, Conclusão e Articulação dos tópicos. Ana Karenina de Melo Arraes Amorim/Magda Dimenstein: Cartografia do funcionamento do serviço residencial terapêutico de Natal.

\section{Referências}

AYRES, J.R. Cuidado e reconstrução das práticas de saúde. Interface - Comunic., Saude, Educ., v.8, n.14, p.73-92, 2004.

DELEUZE, G. Post-scriptum sobre as sociedades de controle. In: DELEUZE, G. Conversações. Rio de Janeiro: Editora 34, 1992. p.219-26.

DELGADO, P. "Instituir a desinstitucionalização": o papel das residências terapêuticas na Reforma brasileira. Cad. IPUB, v.12, n.22, p.19-33, 2007.

FOUCAULT, M. Direito de morte e poder sobre a vida. In: __. História da sexualidade: a vontade de saber. Rio de Janeiro: Graal, 1993. v.1, p.125-49.

HARDT, M. A. Sociedade mundial de controle. In: ALLIEZ, E. (Org.). Gilles Deleuze: uma vida filosófica. São Paulo: Editora 34, 2000. p.357-72.

HARDT, M.; NEGRI, A. Império. São Paulo: Record, 2001.

MACHADO, L.D.; LAVRADOR, M.C.C. Subjetividade e loucura: saberes e fazeres em processo. Vivencia (Natal), n.32, p.79-96, 2007.

. Loucura e subjetividade. In: MACHADO, L.D.; LAVRADOR, M.C.C.; BARROS, M.E.B. (Orgs.). Texturas da Psicologia: subjetividade e política no contemporâneo. São Paulo: Casa do Psicólogo, 2001. p.45-58.

PAULON, S. A desinstitucionalização como transvaloração: apontamentos para uma terapêutica ao niilismo, 2006. Disponível em: <http://antalya.uab.es/athenea>. Acesso em: 20 ago. 2007.

PAULON, S.M. et al. Das múltiplas formas de habitar uma morada. A produção do cuidado em um serviço residencial terapêutico. Vivencia (Natal), n.32, p.119-37, 2007.

ROMAGNOLI, R.C. A resistência como invenção: por uma clínica menor. Vivencia (Natal), n.32, p.97-107, 2007. 
O artigo propõe um debate acerca dos processos de desinstitucionalização no campo da saúde mental, situando-o no contexto da sociedade mundial de controle e das novas formas de poder. A construção de uma rede de atenção que venha a substituir o hospital psiquiátrico é um desafio que estabelece demandas totalmente diversas às encontradas na instituição manicomial. Entretanto, essas alterações por si só não caracterizam a superação da vontade de reproduzir, que insiste na separação entre clínica e política. A invenção de um novo modo de cuidar convoca conhecimentos plurais que superem as fronteiras disciplinares e enfrentem o instituído em cada um de nós. Nesse contexto apresentamos o trabalho realizado em dois Serviços Residenciais Terapêuticos de dois extremos geográficos do país (Porto Alegre e Natal). A partir dessas experiências, acreditamos que a clínica pode ser pensada como plano de produção e campo de experimentação, revelando-se em sua dimensão de resistência micropolítica.

Palavras-chave: Saúde mental. Desinstitucionalização. Clínica contemporânea. Biopolítica. Resistência.

\section{Towards resistance clinics: deinstitutionalizing experimentation in times of biopolitics}

This paper proposes a debate on deinstitutionalization processes within the field of mental health, positioned within the context of worldwide control society and new forms of power. Construction of a care network that would replace psychiatric hospitals is a challenge that establishes demands that are totally different from those found in lunatic asylums. However, these changes in themselves do not characterize the overcoming of the desire to reproduce, with its insistence on separation. Invention of new care methods calls for plural knowledge that surmounts boundaries between disciplines and faces up to what is instituted in each of us. Within this context, we present work carried out in two residential therapeutic services in two geographical extremities of the country (Porto Alegre and Natal). From these experiences, we believe that clinics should be envisaged at the production level and as fields for experimentation, thereby revealing their dimension of micropolitical resistance.

Keywords: Mental health. Deinstitutionalization. Contemporary clinic. Biopolitics. Resistance.

\section{Por una clínica de resistencia: experimentaciones des-institucionalizantes en tiempos de bio-política}

El artículo propone un debate acerca de los procesos de des-institucionalización en el campo de la salud mental, situándolo en el contexto de la sociedad mundial de control y de las nuevas formas de poder. La construcción de una red de atención que vaya a substitutr el hospital psiquiátrico es un desafío que establece demandas totalmente diferentes a las encontradas en la institución del manicomio. No obstante tales alteraciones por si solas no caracterizan la superación de la voluntad de reproducir, que insiste en la separación entre clínica y política. La invención de un nuevo modo de cuidar convoca conocimientos plurales que superen las fronteras disciplinarias y afronten lo instituido en cada uno de nosotros. En este contexto presentarnos el trabajo realizado en dos Servicios Residenciales Terapéuticos de dos extremos geográficos de Brasil (Natal y Porto legre). A partir de tales experiencias creemos que la clínica puede pensarse como plan de producción y campo de experimentación, revelándose en su dimensión de resistancia micro-política.

Palabras clave: Salud mental. Des-institucionalización. Clínica contemporánea. Bio-política. Resistencia.

Recebido em 26/11/2007. Aprovado em 18/06/2008 
